\title{
An Evaluation of Replacing Fish Meal with Fermented Soybean Meal in Diet of Hybrid Snakehead (Channa argus $\times$ Channa maculata): Growth, Nutrient Utilization, Serum Biochemical Indices, Intestinal Histology, and Microbial Community
}

\author{
Zhipeng Duan, ${ }^{1,2,3}$ Chunyan Zhang, ${ }^{1,4}$ Lingling Huang, ${ }^{4}$ Qing Lan, ${ }^{4}$ Jie Hu, ${ }^{4}$ \\ Xiaoqin Li $\mathbb{D}^{1,2,3}$ and Xiangjun Leng $\mathbb{D}^{1,2,3}$ \\ ${ }^{1}$ National Demonstration Center for Experimental Fisheries Science Education, Shanghai Ocean University, \\ Shanghai 201306, China \\ ${ }^{2}$ Centre for Research on Environmental Ecology and Fish Nutrition of Ministry of Agriculture, Shanghai Ocean University, \\ Shanghai 201306, China \\ ${ }^{3}$ Shanghai Collaborative Innovation for Aquatic Animal Genetics and Breeding, Shanghai Ocean University, \\ Shanghai 201306, China \\ ${ }^{4}$ Wilmar (Shanghai) Biotechnology Research \& Development Center Co., Ltd., China
}

Correspondence should be addressed to Xiaoqin Li; xqli@shou.edu.cn and Xiangjun Leng; xjleng@shou.edu.cn

Received 7 November 2021; Revised 9 January 2022; Accepted 13 January 2022; Published 17 February 2022

Academic Editor: Mansour Torfi Mozanzadeh

Copyright (c) 2022 Zhipeng Duan et al. This is an open access article distributed under the Creative Commons Attribution License, which permits unrestricted use, distribution, and reproduction in any medium, provided the original work is properly cited.

The present study investigated the effect of fish meal (FM) replacement with fermented soybean meal (FSM) on growth performance, nutrient utilization, serum biochemical indices, intestinal histology, and microbial community of hybrid snakehead. Five isonitrogenous diets were formulated with FSM inclusion to decrease dietary FM from $350 \mathrm{~g} / \mathrm{kg}$ (the control diet) to $300,250,200$, and $150 \mathrm{~g} / \mathrm{kg}$, referring to CON, FM-30, FM-25, FM-20, and FM-15, respectively, and then fed to hybrid snakehead with initial body weight of $6.49 \pm 0.03 \mathrm{~g}$ for 60 days. The control group showed the best growth with a weight gain rate (WGR) of $417.0 \%$ and a feed conversion ratio (FCR) of 0.84 , but the WGR in FM-25, FM-20, and FM-15 groups was decreased by $26.25 \%, 40.60 \%$, and $42.23 \%$ and FCR was increased by $0.24,0.45$, and 0.45 , respectively, when compared to those in the CON group $(P<0.05)$. The apparent digestibility coefficients of dry matter and crude protein, the protein efficiency and retention, the serum total cholesterol content, and the intestinal muscle thickness in FM-20 and FM-15 groups and the villus height in all FSM groups were significantly lower than those in the CON group $(P<0.05)$. Intestinal microbiota analysis indicated that the main microorganisms included Proteobacteria, Firmicutes, and Actinobacteria. At the genus level, Plesiomonas was the dominant genus with the highest relative abundance in the FM-20 group. In summary, in a diet containing $350 \mathrm{~g} / \mathrm{kg}$ FM, FSM can successfully replace $50 \mathrm{~g} / \mathrm{kg}$ dietary FM without negative effects on growth performance, nutrient utilization, serum biochemical indices, and intestinal health of hybrid snakehead juvenile.

\section{Introduction}

The rapid development of aquaculture has led to an increasing demand for fish meal (FM), but the global FM resources are limited and FM price kept rising in recent years. There- fore, seeking new protein sources to reduce the use of FM has become the focus of aquaculture nutrition and feeds. Soybean meal (SBM) is an important protein source in aquatic feed due to its abundant resources, relatively balanced nutrient composition, and relatively low price [1]. 
However, SBM contains a variety of antinutritional factors, such as glycinin, $\beta$-conglycinin, trypsin inhibitor, and soybean lectin, negatively affecting the digestion and absorption of aquatic animals ([2-4]. In the last decades, fermentation technology has been widely used in the feed industry. After fermenting with microbes, a large number of antinutritional factors in SBM were degraded, while the contents of crude protein, free amino acid, active components such as small peptides, and soybean isoflavones were increased [5-7]. He et al. $[8,9]$ reported that fermented soybean meal (FSM) successfully replaced $105 \mathrm{~g} / \mathrm{kg}$ of FM in a diet containing $350 \mathrm{~g} / \mathrm{kg}$ FM without negative effects on the growth performance, intestinal histology, and microbiota of largemouth bass (Micropterus salmoides). Choi et al. [10] found that the replacement of $100 \mathrm{~g} / \mathrm{kg}$ FM with FSM in a diet containing $250 \mathrm{~g} / \mathrm{kg}$ FM did not adversely affect the growth and feed utilization of rainbow trout (Oncorhynchus mykiss). In black sea bream (Acanthopagrus schlegelii), the partial replacement of dietary FM with FSM showed no significant effects on growth, antioxidant activity, and digestive enzyme activity [11]. In addition, FSM has also effectively partially replaced FM in the diets of Japanese sea bass (Lateolabrax japonicus) [12] and turbot (Scophthalmus maximus) [13].

Snakehead (Channa argus) is a carnivorous fish widely cultured in Asia, including China, Vietnam, Thailand, and India. In 2020, the aquaculture production of snakehead (including hybrid snakehead) reached 501095 tonnes in China [14]. In the market, hybrid snakehead (Channa argus ${ }^{\top} \times C$. maculata ) is the most commonly cultured species, which was obtained from the hybridization of snakehead as the male parent and blotched snakehead (Channa maculata) as the female parent, both belonging to Perciformes, Channidae, Channa. Compared with its parents, hybrid snakehead has higher survival and better stress resistance and growth performance. Generally, the commercial diets for hybrid snakehead contain high level of animal protein ingredients up to $400 \sim 500 \mathrm{~g} / \mathrm{kg}$, including FM, chicken meal, and meat and bone meal.

At present, the previous studies have reported the replacement of FM with SBM [15], soybean protein concentrate [16], and corn protein concentrate [17] in the diets of snakehead or hybrid snakehead, but FSM was not tried. Therefore, in this study, FSM was used to replace different proportions of FM in the diet of hybrid snakehead, and the growth performance, nutrient utilization, serum biochemical index, intestinal histology, and microbiota community were investigated to direct the application of FSM in carnivorous fish feeds.

\section{Materials and Methods}

2.1. Ethics Statement. All the procedures were strictly carried out in accordance with the Regulations of the Experimental Animal Ethics Committee of Shanghai Ocean University and in compliance with regulations by the Institutional Animal Care and Use Committee.

2.2. Experiment Diets and Design. The basal diet (control diet, CON) was designed to contain $350 \mathrm{~g} / \mathrm{kg}$ FM; then, die- tary FM was decreased by FSM to 300, 250, 200, and $150 \mathrm{~g} /$ kg (FM-30, FM-25, FM-20, and FM-15), respectively, to form five isonitrogenous diets. The main ingredients were crushed and sieved through 60 mesh. All solid ingredients, including $0.5 \mathrm{~g} / \mathrm{kg}$ yttrium oxide, were mixed firstly; then, liquid ingredients such as fish oil, soybean oil, and soybean lecithin were added and mixed; then, the mixture was sieved through 40 mesh to distribute components evenly. Finally, $230 \mathrm{~g} / \mathrm{kg}$ water was added and sieved through 10 mesh. The mixture was extruded to form sinking pellet (diameter of $2 \mathrm{~mm}$ ) with a single screw extruder (SLP-45, Fisheries Machinery Instrument Research Institute of Chinese Academy of Fisheries Sciences). The extruding temperature was $90 \pm 5^{\circ} \mathrm{C}$. After pelleting, all experimental diets were airdried naturally in a ventilated and cool place to maintain suitable moisture content and stored in plastic bags at $4^{\circ} \mathrm{C}$ until further use. Yttrium oxide was added in all diets as an inert marker to determine the apparent digestibility of nutrients. The feed formula and proximate composition are shown in Table 1.

FSM was provided by Yihai Kerry (Fangchenggang) Biotechnology Co., Ltd. (Shanghai, China). It was a commercial product obtained from the anaerobic fermentation of lactic acid bacteria such as Lactobacillus plantarum and sterilized soybean meal for 72 hours. The FSM product contained $500.0 \mathrm{~g} / \mathrm{kg}$ crude protein and $10.0 \mathrm{~g} / \mathrm{kg}$ crude lipid. The proximate composition and amino acid profile of FSM are shown in Table 2.

2.3. Fish and Feeding Management. Hybrid snakehead juveniles were purchased from Ruihai Aquaculture Farm (Guangdong, China). After 2 weeks of temporary stocking, 345 fish with an average weight of $6.49 \pm 0.03 \mathrm{~g}$ were randomly divided into 5 treatments with 3 replicates per treatment and 23 fish per replicate. The feeding trial was carried out in 15 tanks $(0.6 \mathrm{~m} \times 0.6 \mathrm{~m} \times 0.5 \mathrm{~m})$, and all tanks were individually aerated with air stone in a recirculating system without direct sunshine. The circulating water passed through the physical filter such as filter stone, filter cloth, and filter cotton and then flowed into each tank with a flowing velocity of $1.2 \mathrm{~L} / \mathrm{min}$. During the feeding period, the fish were fed twice a day (09:00 and 16:00) with a feeding rate of $30 \mathrm{~g} / \mathrm{kg}-40 \mathrm{~g} / \mathrm{kg}$ of body weight, which was adjusted according to the feeding behavior to ensure no feed residue in 5 min after feeding. The feces at the bottom of the tank were siphoned out every day, and the water was renewed $1 / 4$ with aerated tap water every two days. The water temperature $\left(22-28^{\circ} \mathrm{C}\right)$, dissolved oxygen (>6 mg/L), pH (7.5-8.0), ammonia nitrogen $(<0.01 \mathrm{mg} / \mathrm{L})$, and nitrite $(<0.1 \mathrm{mg} / \mathrm{L})$ were monitored daily during the feeding period. The feeding trial was performed in the indoor culture system of the Fish Nutrition Laboratory of Shanghai Ocean University and lasted for $60 \mathrm{~d}$.

2.4. Sample Collection. Before the feeding trial, ten fish were collected and stored at $-20^{\circ} \mathrm{C}$ as initial samples. In the last two weeks of the feeding trial, the intact feces were collected by siphoning between the $2^{\text {nd }}$ and the $3^{\text {rd }}$ hour after feeding and then stored at $-20^{\circ} \mathrm{C}$ for the digestibility measurement. 
TABLE 1: Composition and nutrient levels of experimental diets (air-dry basis, g/kg).

\begin{tabular}{|c|c|c|c|c|c|}
\hline Ingredients & $\mathrm{CON}$ & FM-30 & FM-25 & FM-20 & FM-15 \\
\hline Fish meal $^{1}$ & 350.0 & 300.0 & 250.0 & 200.0 & 150.0 \\
\hline Fermented soybean meal ${ }^{1}$ & 0.0 & 72.0 & 144.0 & 216.0 & 288.0 \\
\hline Wheat flour ${ }^{1}$ & 199.5 & 172.4 & 145.2 & 118.1 & 91.0 \\
\hline Wheat gluten ${ }^{1}$ & 40.0 & 40.0 & 40.0 & 40.0 & 40.0 \\
\hline Soybean meal $^{1}$ & 120.0 & 120.0 & 120.0 & 120.0 & 120.0 \\
\hline Soybean protein concentrate ${ }^{1}$ & 80.0 & 80.0 & 80.0 & 80.0 & 80.0 \\
\hline Beer yeast $^{1}$ & 50.0 & 50.0 & 50.0 & 50.0 & 50.0 \\
\hline Corn gluten meal ${ }^{1}$ & 40.0 & 40.0 & 40.0 & 40.0 & 40.0 \\
\hline Fish oil & 20.0 & 24.0 & 28.0 & 32.0 & 36.0 \\
\hline Soybean oil & 20.0 & 20.0 & 20.0 & 20.0 & 20.0 \\
\hline Soybean lecithin & 20.0 & 20.0 & 20.0 & 20.0 & 20.0 \\
\hline Yeast paste & 30.0 & 30.0 & 30.0 & 30.0 & 30.0 \\
\hline Vitamin premix ${ }^{2}$ & 5.0 & 5.0 & 5.0 & 5.0 & 5.0 \\
\hline Mineral premix ${ }^{3}$ & 25.0 & 25.0 & 25.0 & 25.0 & 25.0 \\
\hline Yttrium oxide & 0.5 & 0.5 & 0.5 & 0.5 & 0.5 \\
\hline L-Lysine, $\mathrm{HCl}$ & 0.0 & 0.6 & 1.3 & 1.8 & 2.4 \\
\hline DL-Methionine & 0.0 & 0.5 & 1.1 & 1.6 & 2.1 \\
\hline Total & 1000.0 & 1000.0 & 1000.0 & 1000.0 & 1000.0 \\
\hline \multicolumn{6}{|l|}{ Proximate composition (g/kg) } \\
\hline Moisture & 87.8 & 86.4 & 79.3 & 86.0 & 79.5 \\
\hline Crude protein & 484.0 & 484.2 & 480.1 & 480.2 & 479.5 \\
\hline Crude lipid & 104.9 & 102.0 & 99.2 & 107.7 & 105.3 \\
\hline Crude ash & 134.3 & 130.6 & 124.0 & 127.6 & 121.6 \\
\hline
\end{tabular}

${ }^{1}$ The protein contents of protein ingredients were as follows: fish meal, $668 \mathrm{~g} / \mathrm{kg}$; fermented soybean meal, $500 \mathrm{~g} / \mathrm{kg}$; wheat flour, $140 \mathrm{~g} / \mathrm{kg}$; wheat gluten, $769 \mathrm{~g} /$ $\mathrm{kg}$; soybean meal, $459 \mathrm{~g} / \mathrm{kg}$; soybean protein concentrate, $654 \mathrm{~g} / \mathrm{kg}$; beer yeast, $464 \mathrm{~g} / \mathrm{kg}$; and corn gluten meal, $595 \mathrm{~g} / \mathrm{kg}$. ${ }^{2} \mathrm{Vitamin} \mathrm{premix}$ (mg or IU/kg diet): VA, $10000 \mathrm{IU} ; \mathrm{VD}_{3}, 3000 \mathrm{IU}$; VE, $150 \mathrm{IU} ; \mathrm{VK}_{3}, 12.75 \mathrm{mg} ; \mathrm{VB}_{1}, 20 \mathrm{mg}$; VB, $20 \mathrm{mg}$; VB 3,100 mg; VB, $22 \mathrm{mg}$; VB $12,0.15 \mathrm{mg}$; inositol, $500 \mathrm{mg}$; biotin, $0.6 \mathrm{mg}$; and folic acid, $8 \mathrm{mg}$. ${ }^{3}$ Mineral premix (mg/kg diet): I, $1.5 \mathrm{mg}$; Mn, $11.45 \mathrm{mg}$; Co, $0.6 \mathrm{mg}$; Cu, $3 \mathrm{mg}$; Zn, $89 \mathrm{mg}$; Se, $0.24 \mathrm{mg}$; Mg, $180 \mathrm{mg}$; and Fe, $63 \mathrm{mg}$.

At the end of the feeding trial, all fish were deprived of diets for 24 hours and then counted and weighed. Nine fish were randomly selected from each tank, and three fish were stored at $-20^{\circ} \mathrm{C}$ for the proximate composition analysis of the whole body. Another three fish were measured in terms of body length, body weight, and visceral weight. The liver was collected and preserved at $-80^{\circ} \mathrm{C}$ to determine liver antioxidant parameters. After the intestinal mesentery was removed and the intestinal contents were washed off with $8.6 \mathrm{~g} / \mathrm{L}$ normal saline, the foregut was collected and preserved at $-80^{\circ} \mathrm{C}$ to determine the activity of digestive enzymes. Blood was taken from the caudal vein of the remaining three fish and centrifuged at $1512 \times g$ for $15 \mathrm{~min}$ at $4^{\circ} \mathrm{C}$; then, the supernatant was stored at $-80^{\circ} \mathrm{C}$ for the determination of biochemical indexes. The foregut was sampled and fixed in Bouin's fixative solution for the intestinal tissue section. After being rinsed with aseptic saline, the hindgut was preserved in liquid nitrogen for intestinal microbiological analysis.

\subsection{Measurement Indicators and Methods}

2.5.1. Growth Performance and Physique Index. Weight gain rate (WGR), survival, specific growth rate (SGR), feed conversion ratio (FCR), condition factor $(K)$, and viscerosomatic index (VSI) were calculated as follows:

$$
\begin{aligned}
& \text { WGR }(\%)=100 \times \frac{\text { final weight }(\mathrm{g})-\text { initial weight }(\mathrm{g})}{\text { initial weight }(\mathrm{g})}, \\
& \text { Survival }(\%)=100 \times\left(\frac{\text { final number of fish }}{\text { initial number of fish }}\right), \\
& \operatorname{SGR}(\% \mathrm{BW} / \text { day }) \\
& =100 \times \frac{\ln \text { final weight }(\mathrm{g})-\ln \text { initial weight }(\mathrm{g})}{\text { days }}, \\
& K\left(\mathrm{~g} / \mathrm{cm}^{3}\right)=100 \times\left[\frac{\text { feed intake }(\mathrm{g})}{\text { weight gain }(\mathrm{g})},\right. \\
& \operatorname{VSI}(\%)=100 \times\left[\frac{\text { final body weight }(\mathrm{g})}{\text { final body length }(\mathrm{cm})^{3}}\right],
\end{aligned}
$$

2.5.2. Proximate Composition of Diets, Whole Body, and Amino Acid Profiles of FSM. Proximate composition of diets and whole body was analyzed according to the Association of Official Analytical Chemists method [18]. Moisture was determined by oven-drying samples at $105^{\circ} \mathrm{C}$ to constant 
TABle 2: Proximate composition and amino acid profile of fermented soybean meal.

\begin{tabular}{lc}
\hline Items & Content $(\mathrm{g} / \mathrm{kg})$ \\
\hline Proximate composition (air-dry basis) & \\
Crude lipid & 10.0 \\
Crude fiber & 32.4 \\
Crude ash & 69.0 \\
Crude protein & 500.0 \\
Moisture & 95.0 \\
Amino acid composition (dry matter basis) & \\
Alanine & 22.2 \\
Arginine & 33.9 \\
Aspartic acid & 54.1 \\
Cystine & 10.6 \\
Glutamic acid & 86.9 \\
Glycine+serine & 44.9 \\
Histidine & 12.2 \\
Leucine & 40.5 \\
Isoleucine & 23.6 \\
Lysine & 28.1 \\
Methionine & 8.40 \\
Phenylalanine+tyrosine & 44.6 \\
Proline & 24.2 \\
Threonine & 19.1 \\
Tryptophan & 6.50 \\
Valine & 23.1 \\
Total amino acid & 482.9 \\
\hline
\end{tabular}

weight. Crude protein was measured by the Kjeldahl method (2300 Auto analyzer, FOSS Tecator, AB, Hoganas, Sweden). Crude ash was measured by the high-temperature burning method at $550^{\circ} \mathrm{C}$ in a muffle furnace (SXL-1008, Shanghai
Jinghong Experimental Equipment Company, China). Crude lipid was determined by the chloroform-methanol extraction method at $50^{\circ} \mathrm{C}$ to constant weight with a vacuum drying oven (DZF-6050, Shanghai Huitai Instrument Manufacturing Company, China).

FSM was hydrolyzed with $6 \mathrm{~mol} / \mathrm{L}$ hydrochloric acid at $110^{\circ} \mathrm{C}$ for $24 \mathrm{~h}$. In addition, some samples were hydrolyzed with $4 \mathrm{~mol} / \mathrm{L}$ lithium hydroxide at $110^{\circ} \mathrm{C}$ for $24 \mathrm{~h}$ for the determination of tryptophan. Then, use the automatic amino acid analyzer (S-433D, Germany) to determine the amino acid content of FSM.

2.5.3. Serum and Liver Parameters. Serum alanine aminotransferase (ALT), aspartate aminotransferase (AST), glucose (GLU), triglyceride (TG), and total cholesterol (TCHO) were determined by using an automatic biochemical analyzer (Chemray 800), and the corresponding kits were produced by Shanghai Haling Biotechnology Co., Ltd. (Shanghai, China).

Frozen liver samples were thawed at $4^{\circ} \mathrm{C}$, then homogenized with nine times volume $(w / v)$ of ice-cold saline $(8.6 \mathrm{~g} / \mathrm{L} \mathrm{NaCl})$, and centrifuged at $1512 \times \mathrm{g}$ for $15 \mathrm{~min}$ at $4^{\circ} \mathrm{C}$. The supernatant was collected to analyze antioxidant parameters. Malondialdehyde (MDA) and total antioxidant capacity (T-AOC) were determined using the kit (Nanjing Jiancheng Biological Co., Ltd.).

2.5.4. Nutrient Retention and Apparent Digestibility Coefficient. After the burning at $900^{\circ} \mathrm{C}$ for 1 hour, feces samples were dissolved in the solution of nitric acid and hydrogen peroxide. Then, yttrium was analyzed by inductivitycoupled plasma optical emission spectroscopy (ICP-OES; Vista MPX; VARIAN) [10].

The apparent digestibility coefficient (ADC) of dry matter $(\mathrm{DM})$ and crude protein $(\mathrm{CP})$, protein retention $(\mathrm{PR})$, and protein efficiency rate (PER) were calculated according to the following formulas:

$$
\begin{aligned}
& \operatorname{ADC} \text { of } \mathrm{DM}(\%)=100 \times\left[\frac{\left(\text { feces } \mathrm{Y}_{2} \mathrm{O}_{3}-\text { dietary } \mathrm{Y}_{2} \mathrm{O}_{3}\right)}{\text { feces } \mathrm{Y}_{2} \mathrm{O}_{3}}\right] \\
& \mathrm{ADC} \text { of } \mathrm{CP}(\%)=100 \times\left[\frac{\left(\text { feces } \mathrm{Y}_{2} \mathrm{O}_{3} \times \text { dietary } \mathrm{CP}-\text { dietary } \mathrm{Y}_{2} \mathrm{O}_{3} \times \text { feces CP }\right)}{\left(\text { feces } \mathrm{Y}_{2} \mathrm{O}_{3} \times \text { dietary } \mathrm{CP}\right)}\right] \\
& \mathrm{PR}(\%)=100 \times \frac{\text { final body weight }(\mathrm{g}) \times \text { crude protein of final fish }- \text { initial body weight }(\mathrm{g}) \times \text { crude protein of initial fish }}{\text { protein intake }(\mathrm{g})}, \\
& \mathrm{PER}=\frac{\text { final body weight }(\mathrm{g})-\text { initial body weight }(\mathrm{g})}{\text { protein intake }(\mathrm{g})} .
\end{aligned}
$$

2.5.5. Intestinal Digestive Enzyme Activity. Frozen anterior intestine samples were thawed at $4^{\circ} \mathrm{C}$, then homogenized with nine times volume $(w / v)$ of ice-cold saline $(8.6 \mathrm{~g} / \mathrm{L}$ $\mathrm{NaCl}$ ), and centrifuged at $1512 \times g$ for $15 \mathrm{~min}$ at $4^{\circ} \mathrm{C}$. The supernatant was collected to analyze digestive enzyme activity in $24 \mathrm{~h}$. Protease activity was measured according to $\mathrm{Su}$ et al. [19], where one unit was defined as $1 \mu \mathrm{g}$ tyrosine released per minute by hydrolyzing casein in phosphate 
TABLE 3: Effects of fermented soybean meal substituting fish meal on growth performance of hybrid snakehead.

\begin{tabular}{lccccc}
\hline Items & CON & FM-30 & FM-25 & FM-20 & FM-15 \\
\hline IBW (g) & $6.50 \pm 0.01$ & $6.50 \pm 0.01$ & $6.49 \pm 0.02$ & $6.50 \pm 0.01$ & $6.5 \pm 0.01$ \\
FBW (g) & $33.60 \pm 0.78^{\mathrm{a}}$ & $32.58 \pm 1.72^{\mathrm{a}}$ & $24.78 \pm 1.28^{\mathrm{b}}$ & $19.96 \pm 1.71^{\mathrm{c}}$ & $19.41 \pm 0.54^{\mathrm{c}}$ \\
WGR (\%) & $417.0 \pm 13.0^{\mathrm{a}}$ & $401.6 \pm 26.9^{\mathrm{a}}$ & $281.5 \pm 20.9^{\mathrm{b}}$ & $204.0 \pm 22.0^{\mathrm{c}}$ & $198.9 \pm 8.9^{\mathrm{c}}$ \\
FCR & $0.84 \pm 0.02^{\mathrm{c}}$ & $0.89 \pm 0.11^{\mathrm{bc}}$ & $1.08 \pm 0.16^{\mathrm{b}}$ & $1.29 \pm 0.01^{\mathrm{a}}$ & $1.29 \pm 0.07^{\mathrm{a}}$ \\
FI (g/fish) & $22.79 \pm 0.15^{\mathrm{a}}$ & $23.19 \pm 1.48^{\mathrm{a}}$ & $19.53 \pm 1.54^{\mathrm{b}}$ & $17.04 \pm 1.63^{\mathrm{c}}$ & $16.61 \pm 0.79^{\mathrm{c}}$ \\
Survival (\%) & $100 \pm 0.00$ & $98.67 \pm 2.30$ & $97.00 \pm 5.20$ & $95.67 \pm 4.51$ & $98.67 \pm 2.31$ \\
SGR (\% BW/day) & $2.74 \pm 0.04^{\mathrm{a}}$ & $2.69 \pm 0.09^{\mathrm{a}}$ & $2.23 \pm 0.09^{\mathrm{b}}$ & $1.87 \pm 0.14^{\mathrm{c}}$ & $1.82 \pm 0.05^{\mathrm{c}}$ \\
K (g/cm $\left.{ }^{3}\right)$ & $1.23 \pm 0.03$ & $1.29 \pm 0.02$ & $1.17 \pm 0.12$ & $1.20 \pm 0.08$ & $1.22 \pm 0.06$ \\
VSI (\%) & $6.29 \pm 0.08$ & $6.5 \pm 0.37$ & $6.36 \pm 0.22$ & $6.4 \pm 0.27$ & $6.18 \pm 0.4$ \\
\hline
\end{tabular}

IBW: initial body weight; FBW: final body weight; WGR: weight gain; FCR: feed conversion ratio; FI: feed intake; SGR: specific growth rate; K: condition factor; VSI: viscerosomatic index. In the same row, values with different letter superscripts indicate significant differences $(P<0.05)$.

buffer at $\mathrm{pH}$ value of 7.2 and reaction temperature of $37^{\circ} \mathrm{C}$ ( $1 \mathrm{mg}$ tissue protein). Amylase was determined by the iodine-starch colorimetric method with a kit produced by Nanjing Jiancheng Bioengineering Institute, and one unit (U/mg prot) was defined as $10 \mathrm{mg}$ of starch hydrolyzed in the reaction with $1 \mathrm{mg}$ tissue protein acting on the substrate for $30 \mathrm{~min}$ at $37^{\circ} \mathrm{C}$.

2.5.6. Intestinal Histology. The tissue was dehydrated in a series of alcohol solutions and embedded in paraffin. Then, sections $(5-6 \mu \mathrm{m})$ were cut and stained with haematoxylineosin and sealed with a neutral gum. The morphological structure of the tissue was observed using an imaging microscope (Nikon YS100), including villus width, height, and muscle thickness. The image was analyzed with the ImageJ 14.0 image analysis software.

2.5.7. Intestinal Microbiota. The intestinal samples were sent to Shanghai Majorbio Bio-Pharm Technology Co., Ltd. for extraction of DNA and PCR amplification by the Illumina MiSeq Sequencing platform. The V3-V4 variable regions of the $16 \mathrm{~S}$ rRNA gene were amplified by PCR with primers 338F ( $5^{\prime}$-ACTCCTACGGGAGGCAGCAG- $\left.3^{\prime}\right)$ and $806 \mathrm{R}$ $\left(5^{\prime}\right.$-GGACTACHVGGGTWTCTAAT- $\left.3^{\prime}\right)$. Purified amplicons were pooled in equimolar and paired-end sequenced $(2 \times 300)$ on the Illumina MiSeq platform (Illumina) according to the standard protocols by Majorbio Bio-Pharm Technology Co., Ltd. Operational taxonomic units (OTUs) were clustered with $97 \%$ similarity cut-off using UPARSE (version $7.1 \mathrm{http}: / /$ drive5.com/uparse/) with a novel "greedy" algorithm that performs chimera filtering and OTU clustering simultaneously. The community composition and community abundance at phylum and genus levels were analyzed on the free online platform of Majorbio Cloud Platform (https://www.majorbio.com).

2.5.8. Statistical Analysis. Excel 2003 and SPSS software (SPSS Inc., Michigan Avenue, Chicago, IL, USA) were used for statistical analysis. The data were expressed in the form of mean \pm standard deviation (SD). Arcsine transformations were conducted on all data expressed as percentages to achieve homogeneity of variance before statistical analysis.
One-way ANOVA was performed at a significance level of 0.05 following confirmation of normality (one-sample Kolmogorov-Smirnov test) and homogeneity of variance (Levene's test). Tukey's procedure was used for multiple comparisons.

\section{Results}

3.1. Growth Performance. As shown in Table 3, the FM-30 group showed the similar WGR, FCR, and SGR to the CON group $(P>0.05)$, while the WGR and SGR of FM-25, FM-20, and FM-15 groups were significantly lower and the FCR was significantly higher than those of the CON group $(P<0.05)$. No significant differences were found in survival, $K$, and VSI among all the groups $(P>0.05)$.

3.2. Whole Body Composition. In Table 4, the moisture content in the FM-25 group was significantly lower than that in FM-20 and FM-15 groups $(P<0.05)$, and the crude lipid content in FM-20 and FM-15 groups was significantly lower than that in the CON group $(P<0.05)$. No significant differences were found in crude ash and crude protein contents among all the groups $(P>0.05)$.

3.3. Nutrient Utilization. With the increasing replacement of fish meal with FSM, the ADCDM, ADCCP, PER, and PR tended to decrease. The FM-30 group showed the similar levels to the CON group $(P>0.05)$, while other groups had significantly lower ADCDM, PER, and PR than the CON group $(P<0.05)$. In FM-20 and FM-15 groups, the ADCCP was also significantly lower than that of the CON group $(P<0.05)$ (Table 5).

3.4. Serum and Liver Biochemical Indices. As shown in Table 6, serum TCHO content tended to decrease with the decrease in dietary FM, and FM-20 and FM-15 groups showed significantly lower values than the CON group $(P<0.05)$. There was no significant difference in the activities of ALT and AST and the contents of GLU and TG among all the groups $(P>0.05)$. In the liver, the MDA content in FM-30, FM-20, and FM-15 groups was significantly lower, while the T-AOC was significantly higher than those in the CON group $(P<0.05)$. 
TABLE 4: Effect of fermented soybean meal substituting fish meal on the whole body composition of hybrid snakehead (fresh weight, g/kg).

\begin{tabular}{lccccc}
\hline Items & CON & FM-30 & FM-25 & FM-20 & FM-15 \\
\hline Moisture & $711.2 \pm 1.0^{\mathrm{ab}}$ & $713.2 \pm 1.3^{\mathrm{ab}}$ & $703.0 \pm 4.9^{\mathrm{b}}$ & $725.6 \pm 5.7^{\mathrm{a}}$ & $718.5 \pm 6.2^{\mathrm{a}}$ \\
Crude ash & $48.2 \pm 3.1$ & $50.3 \pm 3.3$ & $49.9 \pm 1.9$ & $51.7 \pm 1.7$ & $51.1 \pm 1.3$ \\
Crude lipid & $33.8 \pm 2.5^{\mathrm{a}}$ & $33.1 \pm 1.3^{\mathrm{a}}$ & $32.8 \pm 2.5^{\mathrm{a}}$ & $28.1 \pm 1.9^{\mathrm{b}}$ & $27.5 \pm 3.6^{\mathrm{b}}$ \\
Crude protein & $182.7 \pm 0.7$ & $184.1 \pm 0.7$ & $182.4 \pm 3.0$ & $177.7 \pm 6.6$ & $179.7 \pm 5.7$ \\
\hline
\end{tabular}

In the same row, values with different letter superscripts indicate significant differences $(P<0.05)$.

TABLE 5: Effect of fermented soybean meal substituting fish meal on nutrient utilization of hybrid snakehead.

\begin{tabular}{lcccrr}
\hline Items & CON & FM-30 & FM-25 & FM-20 & FM-15 \\
\hline ADCDM (\%) & $78.85 \pm 0.83^{\mathrm{a}}$ & $78.30 \pm 0.39^{\mathrm{ab}}$ & $76.24 \pm 1.66^{\mathrm{b}}$ & $73.58 \pm 0.95^{\mathrm{c}}$ & $73.42 \pm 2.06^{\mathrm{c}}$ \\
ADCCP (\%) & $94.53 \pm 0.11^{\mathrm{a}}$ & $94.48 \pm 0.57^{\mathrm{a}}$ & $93.69 \pm 0.74^{\mathrm{a}}$ & $92.69 \pm 0.22^{\mathrm{b}}$ & $92.47 \pm 0.65^{\mathrm{b}}$ \\
PER & $2.69 \pm 0.06^{\mathrm{a}}$ & $2.51 \pm 0.34^{\mathrm{ab}}$ & $2.06 \pm 0.21^{\mathrm{bc}}$ & $1.75 \pm 0.02^{\mathrm{c}}$ & $1.72 \pm 0.10^{\mathrm{c}}$ \\
PR (\%) & $50.65 \pm 1.00^{\mathrm{a}}$ & $47.76 \pm 6.39^{\mathrm{a}}$ & $39.21 \pm 3.09^{\mathrm{b}}$ & $32.81 \pm 1.67^{\mathrm{b}}$ & $32.81 \pm 3.29^{\mathrm{b}}$ \\
\hline
\end{tabular}

ADCDM: the apparent digestibility coefficient of dry matter; ADCCP: the apparent digestibility coefficient of crude protein; PER: protein efficiency rate; PR: protein retention. In the same row, values with different letter superscripts indicate significant differences $(P<0.05)$.

TABLE 6: Effect of fermented soybean meal substituting fish meal on serum and liver biochemical indices of hybrid snakehead.

\begin{tabular}{|c|c|c|c|c|c|}
\hline Items & $\mathrm{CON}$ & FM-30 & FM-25 & FM-20 & FM-15 \\
\hline \multicolumn{6}{|l|}{ Serum } \\
\hline $\operatorname{ALT}(\mathrm{U} / \mathrm{L})$ & $2.51 \pm 0.20$ & $2.88 \pm 0.30$ & $2.92 \pm 0.26$ & $2.77 \pm 0.32$ & $2.85 \pm 0.44$ \\
\hline AST (U/L) & $33.10 \pm 4.00$ & $28.80 \pm 2.18$ & $28.29 \pm 1.74$ & $35.31 \pm 7.79$ & $31.49 \pm 3.63$ \\
\hline GLU $(\mathrm{mmol} / \mathrm{L})$ & $4.80 \pm 0.70$ & $4.87 \pm 0.30$ & $4.33 \pm 0.42$ & $4.47 \pm 0.47$ & $4.27 \pm 0.55$ \\
\hline TCHO (mmol/L) & $4.76 \pm 0.10^{\mathrm{a}}$ & $4.87 \pm 0.16^{\mathrm{a}}$ & $4.72 \pm 0.26^{\mathrm{ab}}$ & $4.41 \pm 0.08^{\mathrm{bc}}$ & $4.22 \pm 0.20^{c}$ \\
\hline $\mathrm{TG}(\mathrm{mmol} / \mathrm{L})$ & $1.37 \pm 0.14$ & $1.36 \pm 0.24$ & $1.33 \pm 0.13$ & $1.29 \pm 0.40$ & $1.27 \pm 0.13$ \\
\hline \multicolumn{6}{|l|}{ Liver } \\
\hline MDA (nmol/g) & $2.07 \pm 0.04^{\mathrm{a}}$ & $1.85 \pm 0.04^{\mathrm{b}}$ & $2.03 \pm 0.03^{\mathrm{a}}$ & $1.89 \pm 0.08^{\mathrm{b}}$ & $1.86 \pm 0.04^{\mathrm{b}}$ \\
\hline T-AOC $(\mathrm{mmol} / \mathrm{g})$ & $1.64 \pm 0.02^{\mathrm{a}}$ & $1.94 \pm 0.08^{\mathrm{c}}$ & $1.72 \pm 0.06^{\mathrm{ab}}$ & $1.81 \pm 0.10^{\mathrm{b}}$ & $1.77 \pm 0.01^{\mathrm{b}}$ \\
\hline
\end{tabular}

ALT: alanine aminotransferase; AST: aspartate aminotransferase; CLU: glucose; TCHO: total cholesterol; TG: triglyceride; MDA: malondialdehyde; T-AOC: total antioxidant capacity. In the same row, values with different letter superscripts indicate significant differences $(P<0.05)$.

TABLE 7: Effect of fermented soybean meal substituting fish meal on digestive enzymes of hybrid snakehead.

\begin{tabular}{lccccc}
\hline Items & CON & FM-30 & FM-25 & FM-20 & FM-15 \\
\hline Amylase (U/mg prot) & $1.54 \pm 0.13$ & $1.23 \pm 0.10$ & $1.41 \pm 0.20$ & $1.53 \pm 0.18$ & $1.52 \pm 0.22$ \\
Protease (U/mg prot) & $76.70 \pm 5.81^{\mathrm{a}}$ & $67.32 \pm 8.50^{\mathrm{ab}}$ & $59.70 \pm 5.34^{\mathrm{bc}}$ & $51.20 \pm 6.56^{\mathrm{c}}$ & $49.58 \pm 6.58^{\mathrm{c}}$ \\
\hline
\end{tabular}

In the same row, values with different letter superscripts indicate significant differences $(P<0.05)$.

3.5. Intestinal Digestive Enzyme Activity. As shown in Table 7, intestinal protease activity decreased with the decrease in FM content in diet, and the protease activity in FM-25, FM-20, and FM-15 groups was significantly lower than that in the CON group $(P<0.05)$. No significant difference was found in amylase activity among all the groups $(P>0.05)$.

3.6. Intestinal Morphology. The intestinal morphology is shown in Table 8 and Figure 1. The intestinal muscle thickness and villus height decreased with the decrease in the FM inclusion in diet, and muscle thickness in FM-20 and FM-15 groups and villus height in FM-30, FM-25, FM-20, and FM15 groups were significantly lower than those in the CON group $(P<0.05)$. No significant difference was found in villus width among all the groups $(P>0.05)$.

3.7. Intestinal Microbial Community. As shown in Table 9, the coverage index was close to 1 , which indicated that the bacterial community had been fully sampled and the data could represent the bacterial population.

The Venn diagram of OTUs is shown in Figure 2, and the number of OTUs ranged from 1368 to 1536 . The number of common OTUs in CON, FM-30, FM-25, and FM-20 groups was 359, and the number of unique OTUs in CON, FM-30, FM-25, and FM-20 groups was 636, 627, 558, and 516 , respectively. 
TABLE 8: Effect of fermented soybean meal substituting fish meal on intestinal morphology of hybrid snakehead.

\begin{tabular}{|c|c|c|c|c|c|}
\hline Items & $\mathrm{CON}$ & FM-30 & FM-25 & FM-20 & FM-15 \\
\hline Muscle thickness $(\mu \mathrm{m})$ & $68.1 \pm 5.11^{\mathrm{a}}$ & $64.6 \pm 3.79^{\mathrm{a}}$ & $60.8 \pm 3.70^{\mathrm{ab}}$ & $52.3 \pm 7.52^{\mathrm{b}}$ & $50.4 \pm 7.23^{\mathrm{b}}$ \\
\hline Villus height $(\mu \mathrm{m})$ & $554.3 \pm 18.76^{\mathrm{a}}$ & $460.8 \pm 21.28^{\mathrm{b}}$ & $405.3 \pm 28.14^{\mathrm{c}}$ & $399.2 \pm 20.64^{\mathrm{c}}$ & $381.6 \pm 36.13^{\mathrm{c}}$ \\
\hline Villus width $(\mu \mathrm{m})$ & $50.3 \pm 4.12$ & $44.0 \pm 4.24$ & $45.1 \pm 5.38$ & $42.4 \pm 6.92$ & $48.4 \pm 5.41$ \\
\hline
\end{tabular}

In the same row, values with different letter superscripts indicate significant differences $(P<0.05)$.
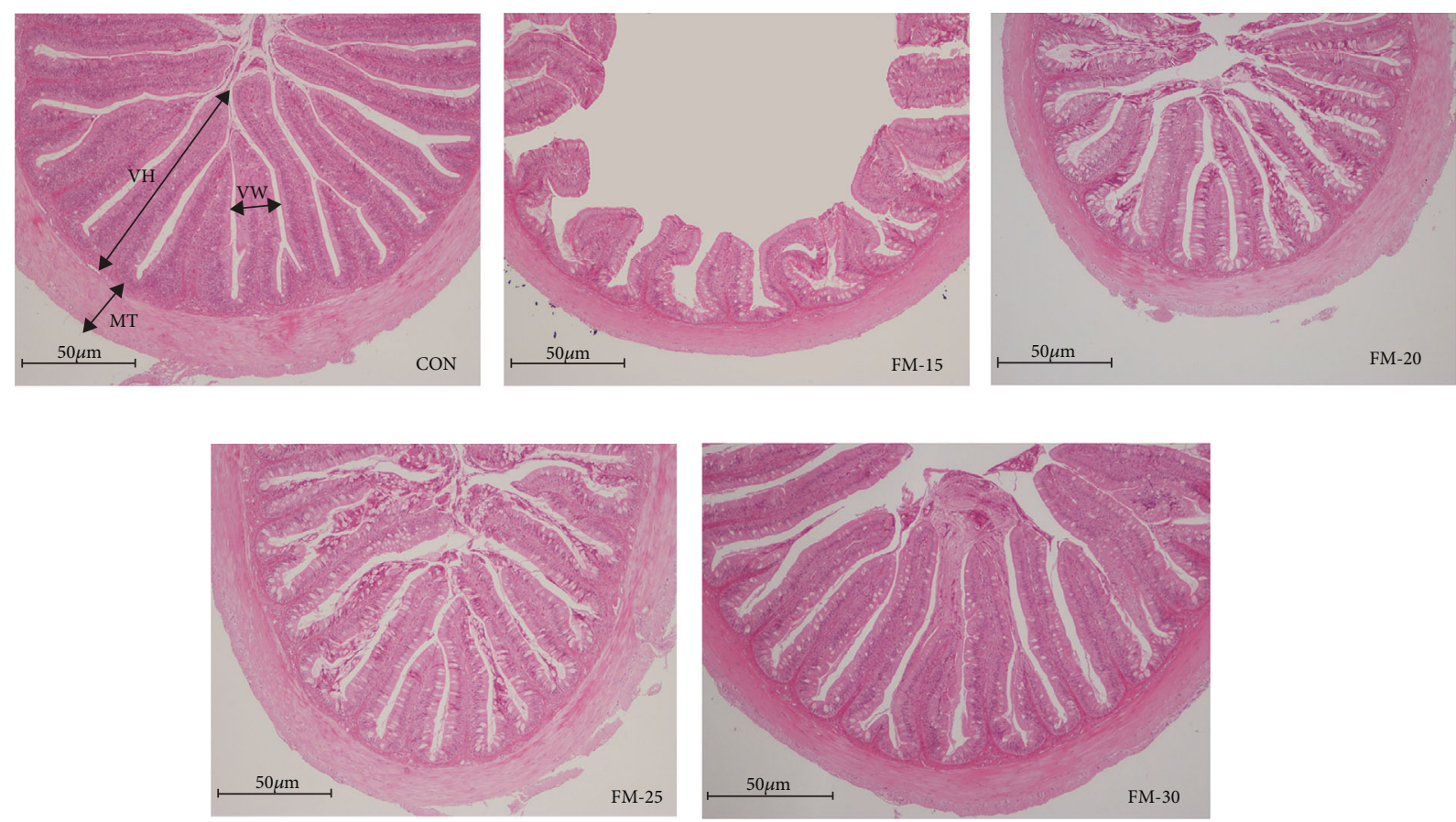

FIGURE 1: Effect of fermented soybean meal substituting fish meal on intestinal morphology of hybrid snakehead. MT: muscular thickness; VH: villus height; VW: villus width.

TABLE 9: Diversity index on OTU level of intestinal microbiota of hybrid snakehead fed with fish meal-substituted diets.

\begin{tabular}{lcccc}
\hline Items & CON & FM-30 & FM-25 & FM-20 \\
\hline Sobs & $671.0 \pm 242.5$ & $655.3 \pm 258.0$ & $633.0 \pm 209.0$ & $608.3 \pm 246.5$ \\
Chao & $688.6 \pm 246.5$ & $678.6 \pm 251.9$ & $655.3 \pm 217.8$ & $638.4 \pm 242.3$ \\
Shannon & $4.16 \pm 0.53$ & $4.76 \pm 0.43$ & $4.46 \pm 0.43$ & $3.80 \pm 2.23$ \\
Simpson & $0.08 \pm 0.05$ & $0.05 \pm 0.03$ & $0.05 \pm 0.03$ & $0.21 \pm 0.33$ \\
Coverage & 0.999 & 0.999 & 0.999 & 0.999 \\
\hline
\end{tabular}

At the phylum level, the intestinal microbiota of all groups was mainly composed of Proteobacteria, Firmicutes, and Actinobacteria (Figure 3). In the CON group, the dominant bacteria were Proteobacteria, accounting for $39.84 \%$ of the total bacteria, followed by Firmicutes (22.04\%) and Actinobacteria $(12.20 \%)$. With the increase in replacement of FM with FSM, the relative abundance of Proteobacteria decreased at first and then increased, while Actinobacteria showed an opposite trend.

At the genus level, intestinal microorganisms mainly included Plesiomonas, Rhodococcus, Thiopseudomonas, Bacillus, Bacteroides, and Cetobacterium (Figure 4). Rhodococcus (5.26\%) and Thiopseudomonas (10.95\%) were the dominant bacteria in the CON group. Compared with the three groups of CON, FM-30, and FM-25, the FM-20 group showed great difference in Plesiomonas, which was the dominant genus in the FM-20 group, accounting for $27.42 \%$ of the total.

\section{Discussion}

4.1. Growth Performance and Nutrient Utilization. In the present study, the replacement of $50 \mathrm{~g} / \mathrm{kg}$ FM with FSM in diet did not affect the growth and feed utilization of juvenile hybrid snakehead, but when the FM replacement level reached $100 \mathrm{~g} / \mathrm{kg}$, a significant decrease in growth was observed. FSM lacks some active substances such as taurine, trimethylamine oxide, and unknown growth factors rich in FM, and the decrease in FM inclusion in diet also reduced 
Venn
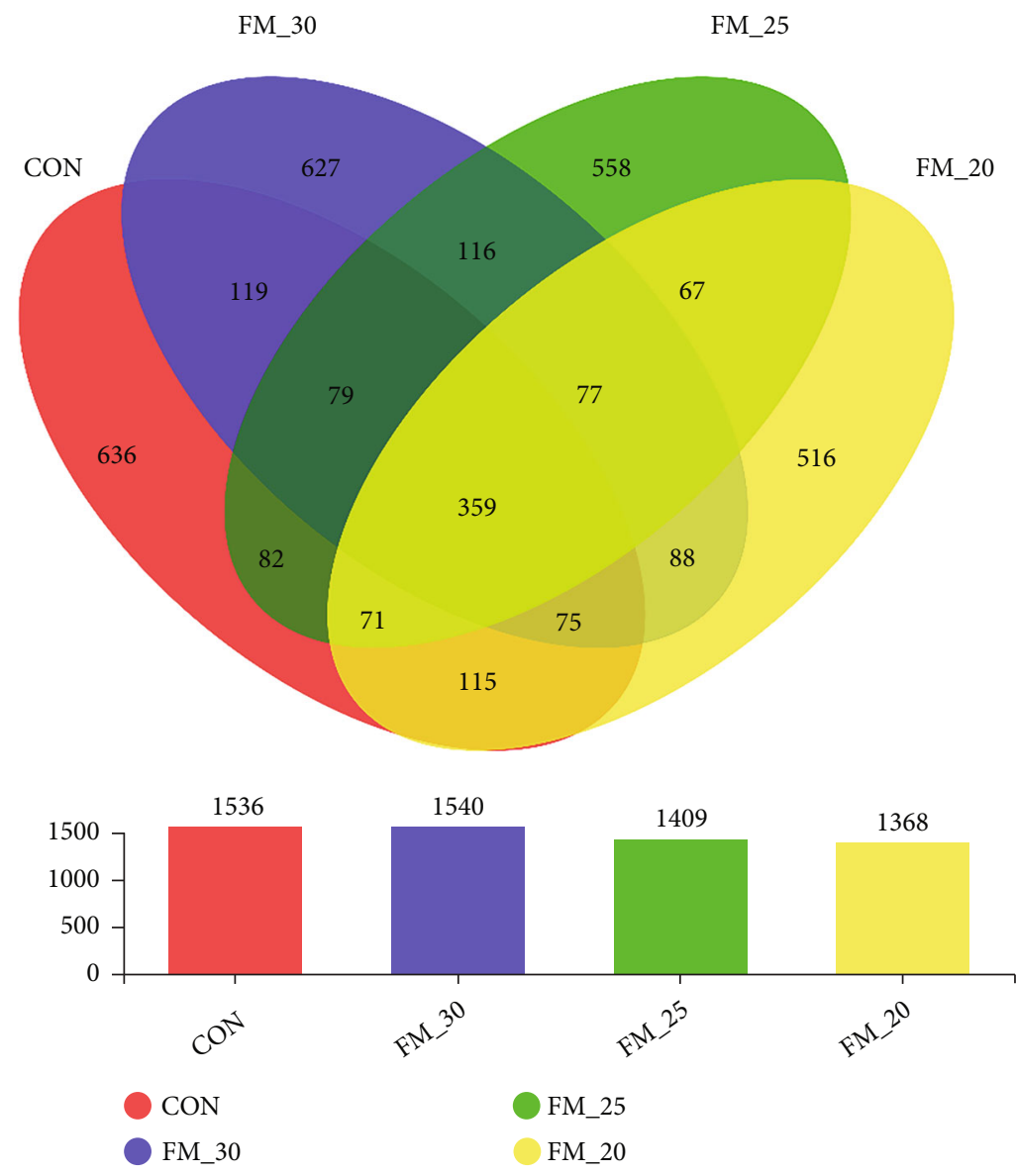

Figure 2: Venn diagram of OTUs of hybrid snakehead fed with fish meal-substituted diets.

the palatability of the feed. Although the dietary requirement of taurine has not been determined, supplementing taurine $(1 \mathrm{~g} / \mathrm{kg})$ to the diet of hybrid snakehead increased the inclusion level of SBM to replace FM [20]. Dietary supplementation of taurine also improved the resisting ability against ammonia stress in hybrid snakehead [21]. In addition, a small amount of antinutritional factors such as saponins and phytin may exist in FSM, although most of them have been degraded by microorganism during the fermentation. Thus, in this study, when FM was replaced by FSM up to $100 \mathrm{~g} / \mathrm{kg}$, the feed intake of hybrid snakehead was significantly decreased and the FCR was significantly increased, leading to a significant decrease in WGR. In rainbow trout, FSM successfully replaced $100 \mathrm{~g} / \mathrm{kg}$ FM in a diet containing $250 \mathrm{~g} / \mathrm{kg}$ FM without adverse effects on the growth and feed efficiency, but higher FM replacement $(150 \mathrm{~g} / \mathrm{kg})$ decreased the growth [10]. He et al. [8, 9] found that FSM could replace $105 \mathrm{~g} / \mathrm{kg}$ FM in a diet containing $350 \mathrm{~g} / \mathrm{kg}$ FM without significant effects on the WGR and feed utilization of largemouth bass. In the present study, the proportion of FSM replacing FM was lower than that of rainbow trout and largemouth bass reported by Choi et al. [10] and He et al. $[8,9]$, which may be related to the small size of fish used in this study and to the high dependence of hybrid sna- kehead on animal protein, especially FM. For juvenile rockfish (Sebastes schlegeli) with body weight of $1.2 \mathrm{~g}$, FSM could replace $58 \mathrm{~g} / \mathrm{kg}$ of dietary FM, while for young rockfish with body weight of $148.2 \mathrm{~g}$, the replacement proportion of FM reached $232 \mathrm{~g} / \mathrm{kg}$ [22], which indicated that the tolerance of juvenile rockfish to FSM was lower than that of bigger fish. The replacement level of FM with FSM depends on dietary FM level, fish species, growth stage, and the supplementation of essential nutrients and active ingredients [23].

In the present study, when the replacement of FM with FSM reached $100 \mathrm{~g} / \mathrm{kg}$, the nutrient digestibility and retention of juvenile hybrid snakehead were decreased significantly. In largemouth bass and rainbow trout, when the FSM inclusion level was $235.2 \mathrm{~g} / \mathrm{kg}$ and $210 \mathrm{~g} / \mathrm{kg}$, the nutrient digestibility and retention also decreased significantly (He et al., [8-10]). This may be related to the lack of active substances such as taurine and unknown growth factors in FSM, which reduced the nourishing effect on the intestinal tract. It has been found that taurine can not only promote the secretion of some hormones and enzymes related to digestion in fish but also make more sulfur-containing amino acids participate in protein synthesis [24]. In addition, the crude fiber content in FSM is much higher than that in FM, which is an important antinutritional factor for 


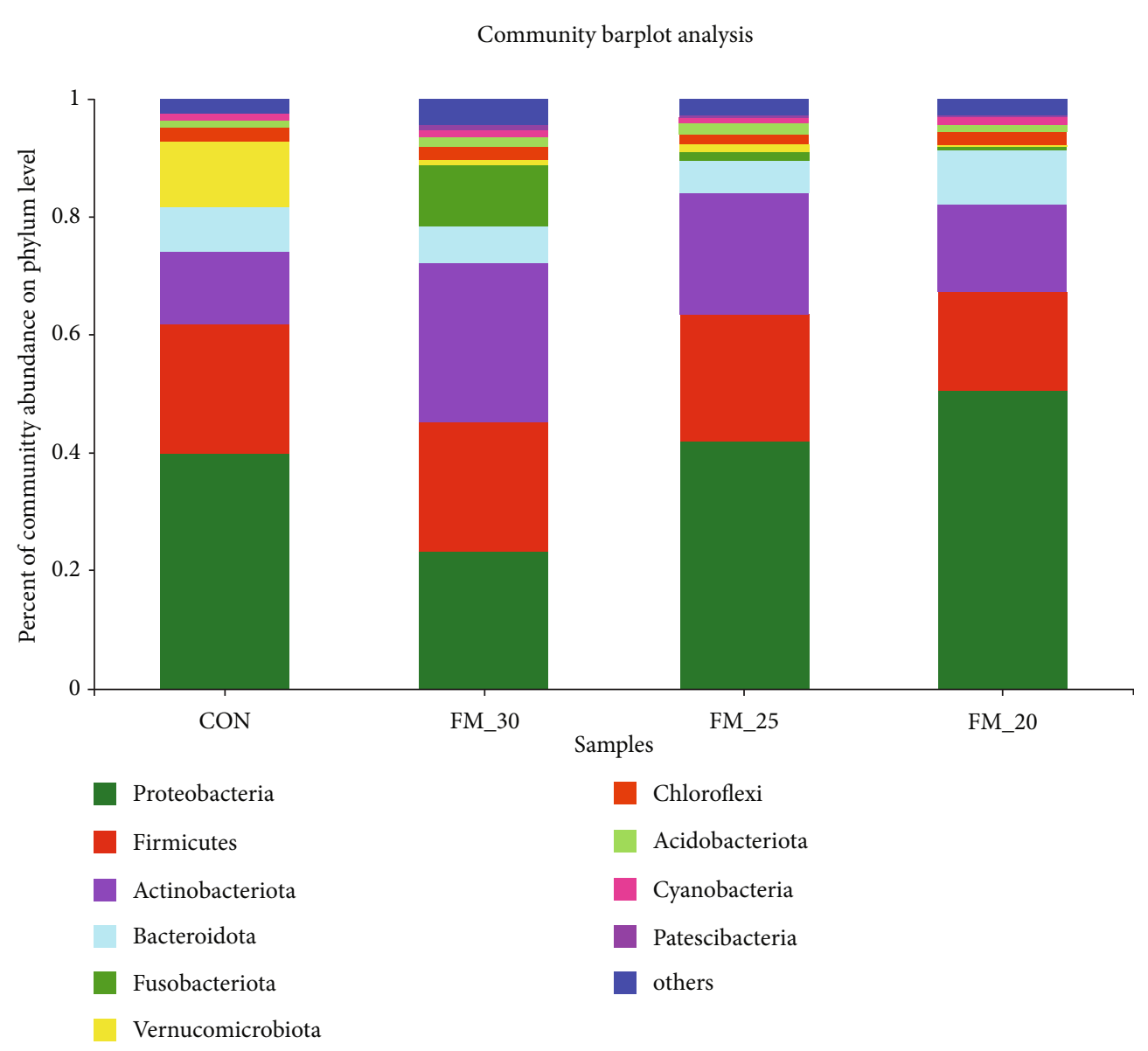

FIgUre 3: Community abundance of intestinal microbiota at the phylum level of hybrid snakehead fed with fish meal-substituted diets.

carnivorous fish. Cherbut et al. [25] found that the decrease in nutrient digestibility caused by plant protein may be related to the increase in cellulose content. High cellulose inclusion in diet will accelerate the emptying rate of chyme in the digestive tract, resulting in the insufficient absorption of nutrients in diets.

4.2. Body Composition and Serum and Liver Biochemical Indices. The present results indicated that the replacement of FM with FSM did not significantly affect the moisture, crude protein, and ash contents in the whole body of juvenile hybrid snakehead, which was similar to the report in rockfish [22]. However, the high replacement of FM with FSM decreased crude lipid content of juvenile black sea bream [26] and the serum TCHO and TG contents of largemouth bass (He et al., $[8,9]$ ). In this study, the crude lipid content of fish and the contents of serum TCHO decreased with the increasing proportion of FSM replacing FM, which may be related to the bioactive peptides existing in FSM. In the process of fermentation, the content of soybean bioactive peptides was increased, which could promote lipid catabolism and inhibit lipid synthesis and storage [27, 28]. In addition, with the increase in the proportion of FSM replacing FM, the feed intake and growth performance of juvenile hybrid snakehead decreased, which also reduced the lipid deposition in the body.
Serum TAOC is a comprehensive index to evaluate the function of the antioxidant system. Lipid peroxidation is the main problem caused by the imbalance of the antioxidant system. MDA, as the final product of lipid peroxidation, has some toxic effects on cells [29]. In the present study, the liver MDA content in FM-30, FM-20, and FM15 groups was significantly lower, while the TAOC was higher than those in the CON group. Ding et al. [30] also found that the replacement of FM with FSM significantly improved the TAOC in the hepatopancreas of Macrobrachium nipponense. FSM contains plenty of isoflavones, which could scavenge free radicals, inhibit lipid peroxidation, and enhance antioxidant capacity [31]. Zhou et al. [32] once reported that dietary supplementation of $40 \mathrm{mg}$ / $\mathrm{kg}$ soybean isoflavones increased the total antioxidant capacity and decreased the MDA content in the liver of golden pompano (Trachinotus ovatus).

4.3. Intestinal Morphology and Digestive Enzyme Activity. The ability of an aquatic species to digest and utilize nutrients is mainly determined by the innate digestive capacity such as gut morphology and digestive enzyme activities. The digestive enzyme activity in the intestine is an important index to reflect the digestive ability of fish, and the height and width of the intestinal villus determine the contact area between mucosal epithelial cells and chyme. The increase in 
Community barplot analysis

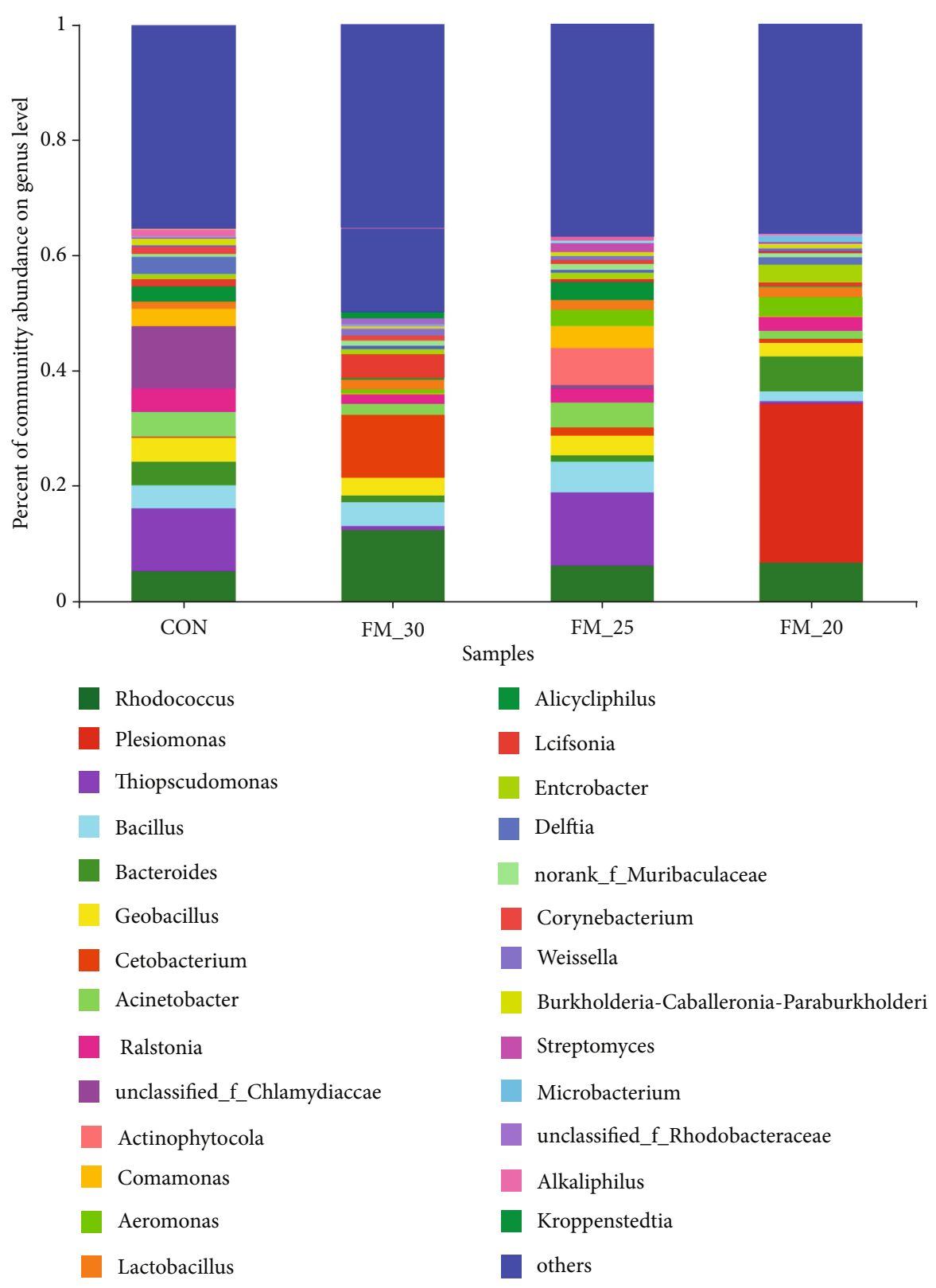

Figure 4: Community abundance of intestinal microbiota at the genus level of hybrid snakehead fed with fish meal-substituted diets.

intestinal muscle thickness is beneficial to the mechanical digestion [33]. The high replacement of FM with FSM significantly decreased intestinal protease activity, muscle thickness, and villus height in the present study, which was similar to the findings in orange-spotted grouper (Epinephelus coioides) [34]. Choi et al. [10] also found that the intestinal protease activity tended to decrease with the increasing FSM, which may be associated with the injured intestinal structure. High levels of FSM in diet altered the structural integrity of the intestinal mucosa and, consequently, resulted in epithelial damage and the reduction of intestinal epithelium absorption capacity. The lack of taurine and bioactive peptides in high FSM diets may be connected with such results. Taurine can promote the secretion of some digestion-related enzymes in fish [24]. It has been reported that the supplementation of taurine in diets increased the trypsin activity of juvenile cobia (Rachycentron canadum) [35] and improved the intestinal structure of black carp (Mylopharyngodon piceus) [36]. In addition, Knudsen et al. [37] suggested that soya saponins were involved in triggering the enteritis response, which may be another reason contributing to the lowered protease activity and damaged intestinal structure.

4.4. Intestinal Microbiota. The stability of intestinal microbiota affects the digestion and absorption, the immunity, and the growth of fishes [38]. In the present study, with the increase in FSM replacing FM, the species richness of 
intestinal microbiota tended to decrease, but no significant effect on the composition of intestinal microbiota was found. In the study of replacing FM and fish oil with mixed plant protein sources and vegetable oils, no significant change in the intestinal microbial composition was observed in European sea bass (Dicentrarchus labrax) [39]. Similarly, the replacement of FM with hydrolyzed wheat protein powder and mixed animal protein did not significantly affect the intestinal microbiota of Asian seabass (Lates calcarifer) [40], and the similar result was also reported in white shrimp (Litopenaeus vannamei) [41].

At the phylum level, the major intestinal microbiota of hybrid snakehead was Proteobacteria, Firmicutes, and Actinobacteria, which was similar to the intestinal microbiota composition of northern snakehead [15]. At the genus level, the intestinal microbiota of hybrid snakehead mainly included Plesiomonas, Rhodococcus, and Thiopseudomonas. Compared with the control group, the relative abundance of Plesiomonas in the FM-20 group increased significantly, reaching $27.42 \%$. Plesiomonas shigelloides is a conditional pathogen, which is considered to be a new pathogen of digestive tract inflammation in many aquatic animals. The reason for the changes may be related to the decrease in species richness and to the insufficient content of taurine in FSM. During intestinal inflammation and immune responses, it has been speculated that dietary FM deficiency induces gut mucosal secretion due to proinflammatory responses that coincide with ex vivo and in vivo gut bacterial translocation. The replacement of dietary FM with FSM might result in gut bacterial translocation due to the inflammatory responses, high mucosal secretion, and structural changes in the gut membrane. Thus, the capacity of firm adhesion of certain bacterial species and their ability to physically cross the gut barrier would be lowered, resulting in the decrease in gut microbiota richness. Taurine has also been shown to regulate gut microecology by inhibiting the growth of harmful bacteria, accelerating the production of short-chain fatty acids, and reducing lipopolysaccharide concentration [42].

\section{Conclusion}

In a basal diet containing $350 \mathrm{~g} / \mathrm{kg}$ FM, FSM can effectively replace $50 \mathrm{~g} / \mathrm{kg}$ FM. Higher proportion of replacement will reduce the growth performance and nutrient utilization and produce adverse effects on the intestinal health of hybrid snakehead.

\section{Data Availability}

All data generated or analyzed during this study are included in this article.

\section{Conflicts of Interest}

The authors declare that they have no conflicts of interest.

\section{Authors' Contributions}

The first author is Zhipeng Duan, and the co-first author is Chunyan Zhang. These authors contribute equally to this work.

\section{Acknowledgments}

This study was financially supported by Wilmar (Shanghai) Biotechnology Research \& Development Center Co., Ltd.

\section{References}

[1] S. Refstie, T. Storebakken, and A. J. Roem, "Feed consumption and conversion in Atlantic salmon (Salmo salar) fed diets with fish meal, extracted soybean meal or soybean meal with reduced content of oligosaccharides, trypsin inhibitors, lectins and soya antigens," Aquaculture, vol. 162, no. 3-4, pp. 301312, 1998.

[2] C. Burrells, P. D. Williams, P. J. Southgate, and V. O. Crampton, "Immunological, physiological and pathological responses of rainbow trout (Oncorhynchus mykiss) to increasing dietary concentrations of soybean proteins," Veterinary Immunology and Immunopathology, vol. 72, no. 3-4, pp. 277-288, 1999.

[3] X. D. Duan, L. Feng, W. D. Jiang et al., "Dietary soybean $\beta$ conglycinin suppresses growth performance and inconsistently triggers apoptosis in the intestine of juvenile grass carp (Ctenopharyngodon idella) in association with ROS-mediated MAPK signalling," Aquaculture Nutrition, vol. 25, no. 4, pp. 770-782, 2019.

[4] H. F. Gemede and N. Ratta, "Antinutritional factors in plant foods: potential health benefits and adverse effects," International Journal of Nutrition and Food Sciences, vol. 3, no. 4, pp. 284-289, 2014.

[5] I. Amadou, M. T. Kamara, A. Tidjani, M. B. K. Foh, and G. W. Le, "Physicochemical and nutritional analysis of fermented soybean protein meal by Lactobacillus plantarum Lp6," World Journal of Dairy \& Food Sciences, vol. 5, no. 2, pp. 114-118, 2010.

[6] C. K. Jones, J. M. DeRouchey, J. L. Nelssen, M. D. Tokach, S. S. Dritz, and R. D. Goodband, "Effects of fermented soybean meal and specialty animal protein sources on nursery pig performance," Journal of Animal Science, vol. 88, no. 5, pp. 17251732, 2010.

[7] Y. S. Song, J. Frías, C. Martinez-Villaluenga, C. Vidal-Valdeverde, and E. G. de Mejia, "Immunoreactivity reduction of soybean meal by fermentation, effect on amino acid composition and antigenicity of commercial soy products," Food Chemistry, vol. 108, no. 2, pp. 571-581, 2008.

[8] M. He, X. Q. Li, L. Poolsawat et al., "Effects of fish meal replaced by fermented soybean meal on growth performance, intestinal histology and microbiota of largemouth bass (Micropterus salmoides)," Aquaculture Nutrition, vol. 26, no. 4, pp. 1058-1071, 2020.

[9] M. He, Y. F. Yu, X. Q. Li et al., “An evaluation of replacing fish meal with fermented soybean meal in the diets of largemouth bass (Micropterus salmoides): growth, nutrition utilization and intestinal histology," Aquaculture Research, vol. 51, no. 10, pp. 4302-4314, 2020.

[10] D. G. Choi, M. He, H. Fang, X. L. Wang, X. Q. Li, and X. J. Leng, "Replacement of fish meal with two fermented soybean 
meals in diets for rainbow trout (Oncorhynchus mykiss)," Aquaculture Nutrition, vol. 26, no. 1, pp. 37-46, 2020.

[11] H. M. Azarm and S. M. Lee, "Effects of partial substitution of dietary fish meal by fermented soybean meal on growth performance, amino acid and biochemical parameters of juvenile black sea breamAcanthopagrus schlegeli," Aquaculture Research, vol. 45, no. 6, pp. 994-1003, 2014.

[12] X. F. Liang, L. Hu, Y. C. Dong et al., "Substitution of fish meal by fermented soybean meal affects the growth performance and flesh quality of Japanese seabass (Lateolabrax japonicus)," Animal Feed Science and Technology, vol. 229, pp. 1-12, 2017.

[13] L. Wang, H. Zhou, R. He, W. Xu, K. Mai, and G. He, "Effects of soybean meal fermentation by Lactobacillus plantarum P8 on growth, immune responses, and intestinal morphology in juvenile turbot (Scophthalmus maximus L.)," Aquaculture, vol. 464, pp. 87-94, 2016.

[14] China Fishery Statistical Yearbook, Fisheries and Fisheries Administration of the Ministry of Agriculture and Rural Affairs, National Fisheries Technology Promotion Station, Chinese Fisheries Society, China Agriculture Press, 2021.

[15] S. Miao, J. Zhu, C. Zhao, L. Sun, X. Dong, and G. Chen, "Effect of dietary soybean meal associated with feeding time on the growth performance and intestinal microbiota composition of northern snakehead," Aquaculture Research, vol. 50, no. 10, pp. 2751-2759, 2019.

[16] T. T. T. Hien, T. M. Phu, T. L. C. Tu, N. V. Tien, P. M. Duc, and D. A. Bengtson, "Effects of replacing fish meal with soya protein concentrate on growth, feed efficiency and digestibility in diets for snakehead, Channa striata," Aquaculture Research, vol. 48, no. 6, pp. 3174-3181, 2017.

[17] H. Xue, Q. Ai, X. Qian, and B. Yun, "Effects of dietary corn gluten meal on growth performance and cholesterol metabolism in juvenile snakehead (Ophiocephalus argus) fed practical diets," Israeli Journal of Aquaculture-Bamidgeh, vol. 67, p. 20731, 2015.

[18] AOAC (Association of Official Analytical Chemists), Official methods of analysis of official analytical chemists international, Association of Official Analytical Chemists, Arlington, VA, USA, 16th edition, 1995.

[19] X. Su, X. Li, X. Leng et al., "The improvement of growth, digestive enzyme activity and disease resistance of white shrimp by the dietary citric acid," Aquaculture International, vol. 22, no. 6, pp. 1823-1835, 2014.

[20] T. T. T. Hien, T. T. Be, C. M. Lee, and D. A. Bengtson, "Development of formulated diets for snakehead (Channa striata and Channa micropeltes): Can phytase and taurine supplementation increase use of soybean meal to replace fish meal?," Aquaculture, vol. 448, pp. 334-340, 2015.

[21] X. Tan, Z. Sun, X. Zhu, and C. Ye, "Dietary supplementation with taurine improves ability to resist ammonia stress in hybrid snakehead (Channa maculatus $+\times$ Channa argus $\left.{ }^{\star}\right)$," Aquaculture Research, vol. 49, no. 10, pp. 3400-3410, 2018.

[22] S. M. Lee, H. M. Azarm, and K. H. Chang, "Effects of dietary inclusion of fermented soybean meal on growth, body composition, antioxidant enzyme activity and disease resistance of rockfish (Sebastes schlegeli)," Aquaculture, vol. 459, pp. 110116, 2016.

[23] L. G. Wang, W. F. Zeng, B. Lou et al., "Effects of replacement of fish meal by fermented soybean meal on growth performance, serum biochemical indices and liver insulin-like growth factorI gene expression of juvenile yellow drum (Nibea albflora),"
Chinese Journal of Animal Nutrition, vol. 30, no. 3, pp. 989998, 2018.

[24] S. Ikuyama, T. Okajima, K. I. Kato, and H. Ibayashi, "Effect of taurine on growth hormone and prolactin secretion in rats: possible interaction with opioid peptidergic system," Life Sciences, vol. 43, no. 10, pp. 807-812, 1988.

[25] C. Cherbut, A. C. Aube, N. Mekki, C. Dubois, D. Lairon, and J. L. Barry, "Digestive and metabolic effects of potato and maize fibres in human subjects," British Journal of Nutrition, vol. 77, no. 1, pp. 33-46, 1997.

[26] F. Zhou, W. Song, Q. Shao et al., "Partial replacement of fish meal by fermented soybean meal in diets for black sea bream, Acanthopagrus schlegelii, juveniles," Journal of the World Aquaculture Society, vol. 42, no. 2, pp. 184-197, 2011.

[27] C. Chatterjee, S. Gleddie, and C. W. Xiao, "Soybean bioactive peptides and their functional properties," Nutrients, vol. 10, no. 9, p. 1211, 2018.

[28] K. Ishihara, "Effect of soybean peptide on suppression of body fat accumulation during endurance swimming in mice," Nutritional Science of Soy Protein, vol. 17, pp. 94-97, 1996.

[29] X. L. Liu, Q. Y. Xi, L. Yang et al., “The effect of dietary Panax ginseng polysaccharide extract on the immune responses in white shrimp, Litopenaeus vannamei," Fish and Shellfish Immunology, vol. 30, no. 2, pp. 495-500, 2011.

[30] Z. Ding, Y. Zhang, J. Ye, Z. Du, and Y. Kong, “An evaluation of replacing fish meal with fermented soybean meal in the diet of Macrobrachium nipponense: Growth, nonspecific immunity, and resistance to Aeromonas hydrophila," Fish \& Shellfish Immunology, vol. 44, no. 1, pp. 295-301, 2015.

[31] R. Yan and T. Wang, "Advanced research of soybean idoflavones on antioxidation of animals," Acta Ecologiae Animalis Domastici, vol. 31, no. 4, pp. 96-100, 2010.

[32] C. Zhou, H. Lin, Z. Huang, J. Wang, Y. Wang, and W. Yu, "Effects of dietary soybean isoflavones on non-specific immune responses and hepatic antioxidant abilities and mRNA expression of two heat shock proteins (HSPs) in juvenile golden pompano Trachinotus ovatus under $\mathrm{pH}$ stress," Fish \& Shellish Immunology, vol. 47, no. 2, pp. 1043-1053, 2015.

[33] Z. Cheng, S. Chen, M. An et al., "Effects of replacing fish meal with soybean meal, with or without dietary arginine, on growth performance, immune indices and intestinal morphology of grouper, Epinephelus malabaricus," Aquaculture and Fisheries Management, vol. 49, no. 9, pp. 2954-2964, 2018.

[34] Y. L. Shiu, S. L. Hsieh, W. C. Guei, Y. T. Tsai, C. H. Chiu, and C. H. Liu, "UsingBacillus subtilisE20-fermented soybean meal as replacement for fish meal in the diet of orange-spotted grouper (Epinephelus coioides, Hamilton)," Aquaculture Research, vol. 46, no. 6, pp. 1403-1416, 2015.

[35] G. Salze, E. McLean, and S. R. Craig, "Dietary taurine enhances growth and digestive enzyme activities in larval cobia," Aquaculture, vol. 362-363, pp. 44-49, 2012.

[36] Q. Tian, Y. Hu, P. Mao, J. Xie, B. Fang, and H. Z. Peng, "Effect of dietary taurine supplementation on growth, intestine structure sand resistance to acute crowding stress in juvenile black carp (Mylopharyngodon piceus) fed low fish meal diets," Journal of Fisheries of China, vol. 40, no. 9, pp. 1330-1339, 2016.

[37] D. Knudsen, P. Urán, A. Arnous, W. Koppe, and H. Frøkiær, "Saponin-containing subfractions of soybean molasses induce enteritis in the distal intestine of Atlantic salmon," Journal of Agricultural and Food Chemistry, vol. 55, no. 6, pp. 22612267, 2007. 
[38] P. De Schryver and O. Vadstein, "Ecological theory as a foundation to control pathogenic invasion in aquaculture," The ISME Journal, vol. 8, no. 12, pp. 2360-2368, 2014.

[39] S. Torrecillas, D. Mompel, M. J. Caballero et al., "Effect of fishmeal and fish oil replacement by vegetable meals and oils on gut health of European sea bass (Dicentrarchus labrax)," Aquaculture, vol. 468, pp. 386-398, 2017.

[40] E. Apper, D. Weissman, F. Respondek et al., "Hydrolysed wheat gluten as part of a diet based on animal and plant proteins supports good growth performance of Asian seabass (Lates calcarifer), without impairing intestinal morphology or microbiota," Aquaculture, vol. 453, pp. 40-48, 2016.

[41] J. Shao, B. Wang, M. Liu, K. Jiang, L. Wang, and M. Wang, "Replacement of fishmeal by fermented soybean meal could enhance the growth performance but not significantly influence the intestinal microbiota of white shrimp Litopenaeus vannamei," Aquaculture, vol. 504, pp. 354-360, 2019.

[42] H. Yu, Z. Guo, S. Shen, and W. Shan, "Effects of taurine on gut microbiota and metabolism in mice," Amino Acids, vol. 48, no. 7, pp. 1601-1617, 2016. 